\title{
Off-pump versus on-pump coronary artery bypass grafting in patients with depressed left ventricular ejection fraction percentage: "If this is the best of all possible worlds, what then are the others?"
}

\author{
Giuseppe D’Ancona, MD, PhD, Stephan Kische, MD, PhD, and Hüseyin Ince, MD, PhD
}

\footnotetext{
From the Vivantes Klinikum im Friedrichshain und Am Urban, Berlin and Rostock University Medical Center Rostock, Germany.

Disclosures: Authors have nothing to disclose with regard to commercial support.

Received for publication Nov 27, 2015; accepted for publication Nov 30, 2015; available ahead of print Jan 9 2016.

Address for reprints: Giuseppe D'Ancona, MD, PhD, Department of Cardiology, Vivantes Klinikum Friedrichshain, Landsberger Allee 49, 10249 Berlin, Germany (E-mail: rgea@ hotmail.com).

J Thorac Cardiovasc Surg 2016;151:1099-100 $0022-5223 / \$ 36.00$

Copyright (C) 2016 by The American Association for Thoracic Surgery http://dx.doi.org/10.1016/j.jtcvs.2015.11.065
}

In this issue of the Journal, Ueki and colleagues ${ }^{2}$ report a retrospective evaluation of data collected in the Japan Adult Cardiovascular Society, the outcomes of off-pump coronary artery bypass grafting (CABG) versus on-pump CABG in patients with depressed left ventricular ejection fraction (left ventricular ejection fraction $<30 \%$ ). Ueki and colleagues ${ }^{2}$ used propensity score matching to identify 918 paired patients and to conclude that off-pump CABG has significantly decreased rates of operative and 30-day mortality, mediastinitis, revision for bleeding, and prolonged ventilation. Although Ueki and colleagues ${ }^{2}$ must be commended for their efforts, we believe that the speculation should be taken even further, beyond the simple premises of their article.

When we look at the broader picture, 2 large prospective, randomized, controlled trials have clearly documented that off-pump CABG does not improve mortality. ${ }^{3,4}$ Although within both cohorts the rate of patients with severely depressed left ventricular ejection fraction was only slightly above $5 \%$, these findings are a benchmark, and in the future we need consistency to prove the benefits of off-pump CABG and justify its adoption for high-risk surgical candidates. Because propensity score matching has to be limited to preoperative variables only, this is a major limitation of the statistical method proposed in the study of Ueki and colleagues. ${ }^{2}$ In fact, patients were not matched for operating surgeon, and we are thus prevented from clearly identifying the real benefits of cardiopulmonary bypass avoidance. Apart from the "pumping" attitudes, how much does really the "surgeon" factor affect outcomes? Are we really testing different techniques, or just different surgeons? From a closer look at the presented data, it emerges that use of bilateral internal thoracic arteries and no-touch aortic technique, both markers of further surgical complexity and personal commitment, were both significantly more common in the off-pump CABG group. These findings reflect the fact that most probably we are dealing mainly with patients who were treated according to 2

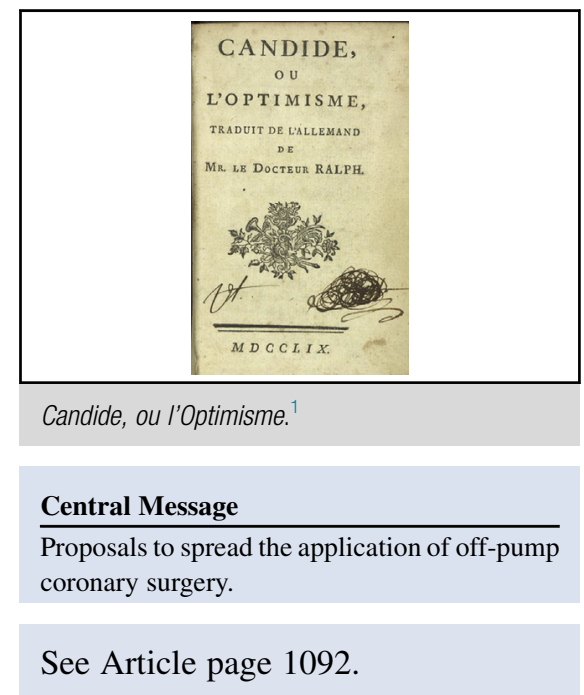

overall different "surgical philosophies." Is it not reasonable to believe that more confident surgeons, with enhanced dexterity and larger experience, will be more likely to treat these complex and fragile patients on the beating heart without the safety net of cardiopulmonary bypass?

If it is sound to believe that avoidance of cardiopulmonary bypass, and eventually cardioplegic arrest, may reduce morbidity and mortality in patients with complex comorbid profiles, such as those with depressed left ventricular ejection fraction, why in most environments is off-pump CABG still performed in less than $20 \%$ of cases $?^{5}$ Why in a reality like that of Japan, where $60 \%$ of the patients are treated off pump, is there still such a high rate of use of cardiopulmonary bypass in patients with depressed ventricular function?

The surgeon factor is the most important one, and most surgeons are probably still concerned about periprocedural hemodynamic instability and technical challenges, especially when revascularizing the more lateral and posterior coronary branches, particularly in patients with a labile hemodynamic equilibrium. Intraoperative management of off-pump cases in fact entails peculiar skills that should be mastered in stable clinical scenarios and should be maintained over time. Expecting to achieve satisfactory results by performing one-off procedures for selected high-risk patients is unrealistic and will lead to suboptimal results, including anastomotic failure, hemodynamic derangements, and a high rate of emergency conversions to 
cardiopulmonary bypass, which will actually lead to an almost tripled mortality. ${ }^{2}$ This statement acquires further importance when we consider that in most current practices, patency of the newly constructed coronary anastomoses is not routinely and intraoperatively documented by means of the existing tools for intraoperative graft patency verification. ${ }^{6}$

Shall we just believe that this is really "the best of all possible worlds?" ${ }^{1}$ Do we have alternatives to support the wider application of off-pump coronary surgery? How can we stimulate surgeons to consider minimally invasive approaches that will maintain, at the same time, surgical feasibility and hemodynamic stability and will guarantee adequate anastomosis performance and quality control? In this context, when compared with conventional on-pump coronary surgery, hybrid coronary revascularization is associated, in patients at intermediate surgical risk, with lower rates of in-hospital major morbidity, lower blood transfusion use, lower chest tube drainage, and shorter postoperative stay. ${ }^{7,8}$ These findings are all confirmed in the study of Ueki and colleagues, ${ }^{2}$ in which avoidance of cardiopulmonary bypass is associated with a significantly lower incidence of reoperation for bleeding, perioperative transfusion, mediastinitis, prolonged ventilation, and prolonged intensive care unit stay. Ueki and colleagues ${ }^{2}$ actually suggest that a decrease in transfusion requirement might explain the reduced mortality in the off-pump cohort.

Hybrid coronary revascularization, whenever feasible, includes numerous features that can justify and support a wider application of off-pump surgery, even in centers that mainly have an on-pump strategy. There are at least 2 reasons that can explain the logic behind hybrid coronary revascularization. First, performing a single anastomosis on the anterior surface of the heart is, for the average surgeon, technically less challenging and does not imply excessive cardiac manipulation that may lead to hemodynamic derangements, especially in patients with depressed ventricular function. Second, consequent percutaneous coronary intervention on the remaining targets will allow almost immediate quality control of the performed coronary anastomosis and prompt treatment, either by percutaneous or surgical means, of eventual technical failures.

In conclusion, although off-pump coronary revascularization may improve outcomes in patients with depressed ventricular function, its application remains limited and mainly at the discretion of the operating surgeon. We should not accept passively the status quo and believe that this is the "best of all possible worlds." ${ }^{1}$ We need the necessary "optimism," intellectual maturity, and unbiased scientific curiosity to investigate whether there are "better worlds" and other innovations, such as for example hybrid coronary revascularization, that can facilitate treatment of coronary artery disease in high-risk patients and that can actually support a wider and safer application of off-pump coronary surgery.

\section{References}

1. Arouet FM. Candide, ou l'optimisme, traduit de l'Allemand de Mr le Docteur Ralph. 1st ed. Geneva: Cramer; 1759.

2. Ueki C, Miyata H, Motomura N, Sakaguchi G, Akimoto T, Takamoto S. Off-pump versus on-pump coronary artery bypass grafting in patients with left ventricular dysfunction. J Thorac Cardiovasc Surg. 2016;151:1092-8.

3. Shroyer AL, Grover FL, Hattler B, Collins JF, McDonald GO, Kozora E, et al; Veterans Affairs Randomized On/Off Bypass (ROOBY) Study Group. On-pump versus off-pump coronary-artery bypass surgery. N Engl J Med. 2009;361: 1827-37.

4. Lamy A, Devereaux PJ, Prabhakaran D, Taggart DP, Hu S, Paolasso E, et al; CORONARY Investigators. Off-pump or on-pump coronary-artery bypass grafting at 30 days. $N$ Engl J Med. 2012;366:1489-97.

5. Keeling WB, Williams ML, Slaughter MS, Zhao Y, Puskas JD. Off-pump and onpump coronary revascularization in patients with low ejection fraction: a report from the Society of Thoracic Surgeons national database. Ann Thorac Surg. 2013;96:83-8; discussion 88-9.

6. D’Ancona G, Karamanoukian HL, Ricci M, Schmid S, Spanu I, Apfel L, et al. Intraoperative graft patency verification: should you trust your fingertips? Heart Surg Forum. 2000;3:99-102.

7. Harskamp RE, Vassiliades TA, Mehta RH, de Winter RJ, Lopes RD, Xian Y, et al Comparative effectiveness of hybrid coronary revascularization vs coronary artery bypass grafting. J Am Coll Surg. 2015;221:326-34.e1.

8. Harskamp RE, Bagai A, Halkos ME, Rao SV, Bachinsky WB, Patel MR, et al. Clinical outcomes after hybrid coronary revascularization versus coronary artery bypass surgery: a meta-analysis of 1,190 patients. Am Heart J. 2014;167:585-92. 